\title{
STUDENTSKA PLATFORMA - ePORTFOLIO
}

\author{
Stevo Jokić, \\ Aleksandar Sandro Cvetković, \\ Saša Adamović
}

Fakultet za računarstvo i informatiku, Univerzitet Sinergija,

Bijeljina, Bosna i Hercegovina

\section{Rezime:}

Brze promene u tehnologiji uticale su na promene u poslovnom svetu IT industrije koje su se odrazile na visoko obrazovanje i studente. Konstantno učenje i napredovanje, upravljanje karijerom i digitalne kompetencije su veštine koje se danas izdvajaju kao najvažnije. Ovakve veštine se mogu postići uključivanjem studenata u razne projekte i kreiranjem studentskih ePortfolio profila koji će služiti kao dokaz radnih aktivnosti studenata. U ovom radu autori opisuju i predstavljaju ePortfolio rešenje Univerziteta Sinergija na osnovu sumiranog istraživanja koje su sproveli. U radu je objašnjeno od čega se sastoji predloženo ePortfolio rešenje i koje sve mogućnosti pruža. Rezultati rada navode koje sve prednosti ePortfolio platforma omogućava i koliko je ovakva platforma značajna za profesore, studente i poslodavce.

Ključne reči:

ePortfolio platforma, studenti, projekti, razvoj karijere, CV.

\section{UVOD}

Studentski ePortfolio je jedan od vrednih resursa koje svaki Univerzitet treba da poseduje. To je jedan veoma važan resurs koji koji služi za čuvanje podataka odnosno arhiviranje različitih studentskih projekata kao što su: razvoj aplikacija, razvoja baza podataka, pisanje naučnih radova, sertifikata, znanja iz stranih jezika i još mnogo toga. Za studenta kao pojedinca je ovo od izuzetnog značaja u razvoju njegove karijere jer na veoma pristupačan način omogućava svoje javno predstavljanje poslodavcima. Ova platforma ima potencijal da prikaže profesionalni i lični rad svakog pojedinca kao i da ilustruje praksu zasnovanu na dokazima. Period od završetka srednje škole do diplomiranja na fakultetu za studente predstavlja ambiciozan put ka usavršavanju, počevši od izbora fakulteta odnosno nauke koju žele da izučavaju. [1]

Platforma ima različite primene pa tako postoje i različite vrste ePortfolia a to su: radni portfolio, portfolio za prikazavanje rezultata i portfolio procene. Ovi tipovi se teorijski razlikuju ali često dolazi do njihovog preklapanja u praksi. Sam naziv radni portfolio nazvan je po tome jer sadrži radove koji su toku izrade, kao i gotove uzorke radova. Na osnovu toga on se dalje može predstavljati kao portfolio za prikaz. Ukoliko se uporedi radni portfolio sa radnim direktorijumom može se reći da služe koliko e-pošta:

sjokic@sinergija.edu.ba 
sličnoj toliko i različitoj svrsi. Za radni direktorijum jedino zaduženje je sakupljanje posla za svakog pojedinca a nema nikakvu svrhu upotrebe, dok je radni portfolio kolekcija radova vođena ciljevima učenja. Glavna svrha radnog portfolia je da čuva studentske radove. Delovi koji se odnose na određenu temu se čuvaju ovde dok se ne prebace u portfolio za prikazivanje. Na ovaj način profesor može otktriti slabe i jake strane svojih studenata. Primarna publika za ovaj portfolio je student kao i profesori koji ga vode tokom školovanja. Radeći na svojim projektima i šta će biti prikazano studenti postaju samouvereniji i ambiciozniji. Važna publika mogu biti i roditelji koji imaju mogućnost praćenja toka studiranja svoje dece, pogotovo za one roditelje koja ne prihvataju ograničenja trenutnih veština svoj dece ili nemaju realnu sliku načina na koji njihovo dete napreduje u odnosu na drugu decu. Radni portfolio je struktuiran oko jedne određene oblasti. Radovi iz te oblasti se sakupljaju i dokumentuje se napredak studenta.

Najbolja upotreba ePortfolia je prikazivanje najboljih radova studenata odnosno diplomaca. Svrha ove platforme je da se pokaže najviši nivo dostignuća koje je student tokom školovanja postigao. Ova vrsta portfolia se nekim pravilima menja iz godine u godinu iz razloga jer svake naredne godine student treba da ubaci svoje nove projekte na kojima je radio tokom školske godine i koji trebaju da ga predstavljaju za tržište rada. Projekti na kojima se rade mogu se odnositi na stručne predmete koje student pohađa na svom fakultetu uz mentorstvo profesora koji je angažovan tom predmetu. Što se tiče publike koja je značajna za ovu vrstu portfolia prvo su bitni studenti, jer na taj način mogu da prate napredak razvoja pojedinca. Druga, važnija publika koja se tiče studenata-diplomaca su poslodavci, jer poslodavac može da odluči da li će kandidat biti pozvan za razgovor na posao nakon prvog utiska pregledanih radova, biografije, stranih jezika, CV video zapisa itd. Proces rada eportfolia je da mentor odnosno profesor stručnog predmeta prati i nadgleda rad studenta tokom semestra. $\mathrm{Na}$ kraju student mentoru elektornskim putem prilaže sav materijal koji uradio što obuhvata kratak opis projekta, slike projekta, sam projekat koji radio, tehnologije koje je koristio, dokumentaciju projekta i na osnovu svih sakupljenih materijala mentor odlučuje da li je taj rad vredan materijal koji student treba da postavi na svoj lični profil platforme ePortfolia.

U portfolio procene može se dokumentovati šta je student savladao tokom slušanja određenog predmeta, zatim komentari i preporuke mentora koji ga je vodio tokom rada na projektu. Njegova primarna svrha je da ocenjuje i dokumentuje napredak studenta na određenim predmetima. Ta procena može da se vrši tokom jednog semestra ili tokom cele školske godine u zavinosti od tipa projekta koji se radi što uključuje kombinaciju predmeta informacionim tehnolgojima gde se nekoliko predmeta sluša kroz jednu ili dve godine da bi se postigao neki konačan cilj. Što se tiče publike koja je zadužena za ovu vrstu portfolia može biti sam profesor koji ocenjuje rad studenta ali još važnije je da postoji publika koja nije imala dodira sa njima radi realne procene kvaliteta. Profesor može biti zadovoljan ispunjenim kriterijumima međutim ostala publika iz iste struke će dati značajanost ukoliko pozitivno oceni rad. Ta publika može biti: profesori sa fakulteta, državni organi, ostale kolege studenti starijih generacija, alumnisti fakulteta koji su već zaposleni na tržištu rada itd. [2]

Sve tri vrste koje su navedene do sada se preklapaju u jednu celinu a to je ePortfolio platforma. Danas, profesionalci u mnogim oblastima kao što je obrazovanje, umetnost, informacione tehnologije već dugo koriste portfolie kao sredstvo za prikazivanje svojih radova potencijalnim poslodavcima ili klijentima. Studenti informacionih tehnologija se susreću sa različitim predmetnim tehnologijama i često koriste poslovnu mrežu Linkedin kao sredstvo za sopstvenu prezentaciju i traženje posla. Navešćemo nekoliko razloga zašto je korisno posedovati platformu ePortfolio unutar Univerziteta a posebno se odnosi na studente koji izučavaju različite informacione tehnologije.

Građenjem ePortfolia studenti mogu kritički i kreativno razmišljati o svojim akademskim i ličnim dostignućima. Mnogi studenti neće razmišljati na taj način dok ne dođu u proces traženja posla a u tom trenutku važna stvar za njih je da se pokušaju pronaći što kvalitetniji delovi koji će govoriti o njihovi veštinama i sposobnostima. Sa druge strane, studenti koji kroz fakultetsko obrazovanje rade na svom ePortfoliu oni imaju stalan uvid u njihove radove te na osnovu toga mogu razmotriti delove koji najbolje ilustruju njihove talente i sposobnosti.

Studentima je današnje vreme upotrebom informacionih tehnologija znatno lakše poslati svoj ePortfolio poslodavcu putem email-a ili slanjem adrese linka na kojoj se njihov lični profil nalazi. Ovo je važno napomenuti jer studenti informacionih tehnologija već na trećoj godmentorini imaju pravo konkurisati za poslove radi obavljanja stručne prakse. Na veoma brz i efikasan način dostavljaju se svi mogući podaci o osobi za koje je nekad ranije trebalo mnogo više vremena da se dostavi. Pomoću dobro osmišljene elektronske platforme ePortfolia 
studenti poseduju jedan atraktivan paket koji o njima govori sve što treba da se predstave na tržištu rada. [3]

\section{PREGLED U OBLASTI ISTRAŽIVANJA}

Autori [4] su utvrdili da je ePortfolio danas postao mnogo više od običnog skladištenja informacija o studentima. Kreiranjem sopstvenih profila povećavaju svoje prisustvo na tržištu. Nakon što se studentima daju smernice kako kreirati sopstveni portfolio neophodno je objasniti etičko korištenje online informacija. Ove smernice utiču na poboljšanje rada i kvalitet studenta odnosno razumevanju digitalne etike.

Autor [5] smatra da kreiranje portfolia predstavlja izuzetan napredak u visokom obrazovanju, gde se upotrebom inofrmacionih tehnologija došlo do sjajnog rešenja za poboljšanje kvaliteta rada i napredak studenata. Istražene su značajne razlike između klasičnog ePortfolia i online platforme jer studenti danas dolaze u takav sektor gde se od njih očekuje iskustvo u radu u određenoj oblasti što se posebno odnosi na sektor informacionih tehnologija. Rad profesora treba biti usmeren na pružanje takve informacije studentima ali neophodna je i adaptacija profesora na takav sistem rada sa studentima tokom njihovog školovanja.

Autori [6] predstavljaju ePortfolio kao novo digitalno okruženje u odnosu na tradicionalni portfolio koji je služio samo za prikazivanje informacija. Danas, on služi za upravljanje svim oblicima i vrstama dokumenata u digitalnom okruženju i softverskih aplikacija koje služe za sastavljanje tih dokumenata za određenu svrhu. Obe stvari u suštini služe za pružanje i stvaranje znanja. Ovaj naučni rad, na osnovu iskustava korišćenja elektornskog portfolia prikazuje kako se ePortfolio može koristiti za rešavanje izazova i problema sa kojima se suočava individualni kontekst stvaranja znanja.

Autori [7] su elektronski portfolio predstavili kao fokus učenja, istražavanja studenata koji sami biraju šta je vredno postaviti kao dokaz o znanju iz određene oblasti bilo da se to odnosi na projekte, radove, veštine. Dokazano je elektornski portfolio realan način da se dokumentuje stvarni napredak studenata, da se prikažu njihovi najbolji radovi, profesionalno predstavljanje na tržištu rada i da se obezbedi metod ishoda učenja studenata kao i evaluacija nastavnog plana i programa. Samim usvajanjem ovog načina rada sa studentima predstavlja značajan aganžman koji zahteva dobro smišljenu strategiju razvoja. Model koji je predstavljen u ovom radu se zove pentagonalni model koji uključuje pet nivoa. Prvi nivo je identifikacija potreba, drugi nivo služi za određivanje, procenu i budžetiranje, treći nivo je izbor sistema i strateško planiranje, četvrti nivo obuhvata razvoj i peti nivo implementacija i dalji razvoj.

Autor [8] prema istraživanju navodi da većina današnjih Univerziteta širom sveta uvode obrazovne proemene u svoju nastavnu praksu kao i u samu strategiju ocenjivanja studenata. ePortfolio je princip bolonjskog rada, učenja i polaganja predmeta koji se mogu porediti jer na kraju imaju sličan zadatak a to je da student na najbolji mogući način savlada materiju. Tu postiji i drugi aspekti ove platforme kao što je mobilnost studenata, stoga je razvijanje efikasne upotrebe ove platforme u obrazovanju postala važan izazov. $\mathrm{Na}$ osnovu ovih zaključaka tema ovog rada bila je da se identifikuju karakteristike okruženja za učenje prilikom primene ePortfolia za nastavu i karakteristiek studenata koje bi mogle da utiču na njihovo učenje.

\section{PREDLOŽENO REŠENJE}

Univerzitet Sinergija je prepoznao prednosti koje studentski ePortfolio omogućava i prateći svetske trendove započeo projekat izrade ePortfolia. Na Univerzitetu Sinergija u sklopu Fakulteta za računarstvo i informatiku studenti još od prve godine počinju da rade na konkretnim projektima iz svakog stručnog predmeta što se pokazalo kao idealno za implementaciju ePortfolia.

Razvoj ePortfolio projekta realizovan je pomoću web tehnologije WordPress CMS u kombinaciji sa custom delovima koda upotrebom PHP, HTML5, CSS3, JavaScript i MySQL-a.

ePortfolio Univerziteta Sinergija sastoji se od:

- početne strane

- liste studenata

- registracije

- prijave

- admin panela

Početna strana (engl. landing page) sastoji se od četiri sekcije koje sadrže najvažnije informacije vezane za studente poput kako postati član studentske kancelarije Univerziteta Sinergija, šta je sve potrebno? Kako postati član Alumni asocijacije i kako se povezati sa alumnistima, kratak uvod u ePortfolio, pregled svih uspešnih studenata i alumnista, kontakt obrazac za dodatne informacije i listu svih besplatnih kurseva koji se redovno organizuju na Univerzitetu (Slika 1). 


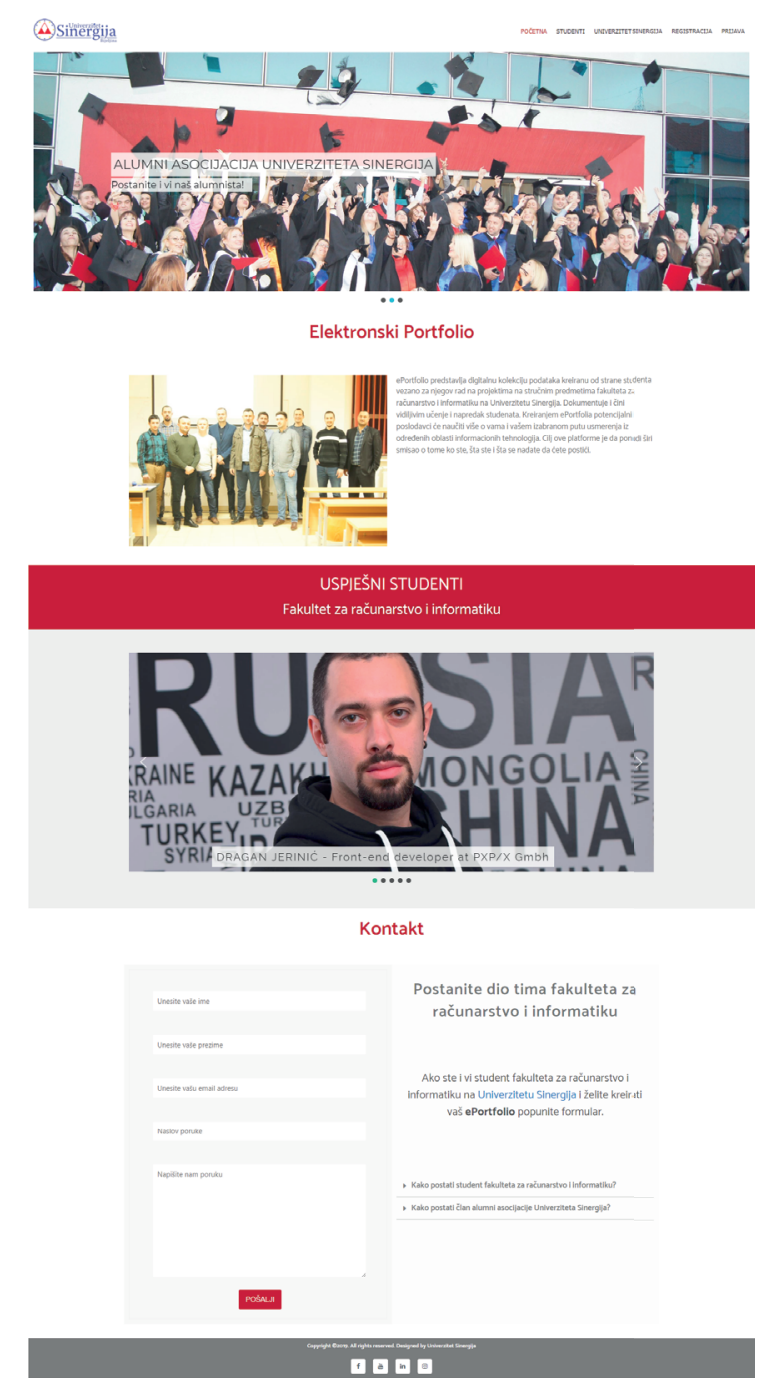

Slika 1. Početna strana

Strana „Studenti“ bazirana je na prikazu studentskih profila. Na jednom mestu grupisani su svi studentski ePortfolio profili. Studenti prilikom kreiranja njihovih profila imaju mogućnost da dodaju stručne veštine koje poseduju (npr. HTML5, CSS3, JavaScript) na osnovu kojih posetioci ePortfolia mogu vršiti pretragu njihovih profila (Slika 2). Sve stručne veštine koje studenti dodaju moraju prvo da budu odobrene od strane mentora.

Studenti imaju mogućnost da kreiraju sopstvene ePortfolio profile ali kako bi kreirali profil potrebno je prvo da se registruju. Strana „Registracija“ omogućava verifikaciju studenata za ePortfolio i samo studenti imaju mogućnost registracije (Slika 3). Administratori upravljaju kontrolom registracije.

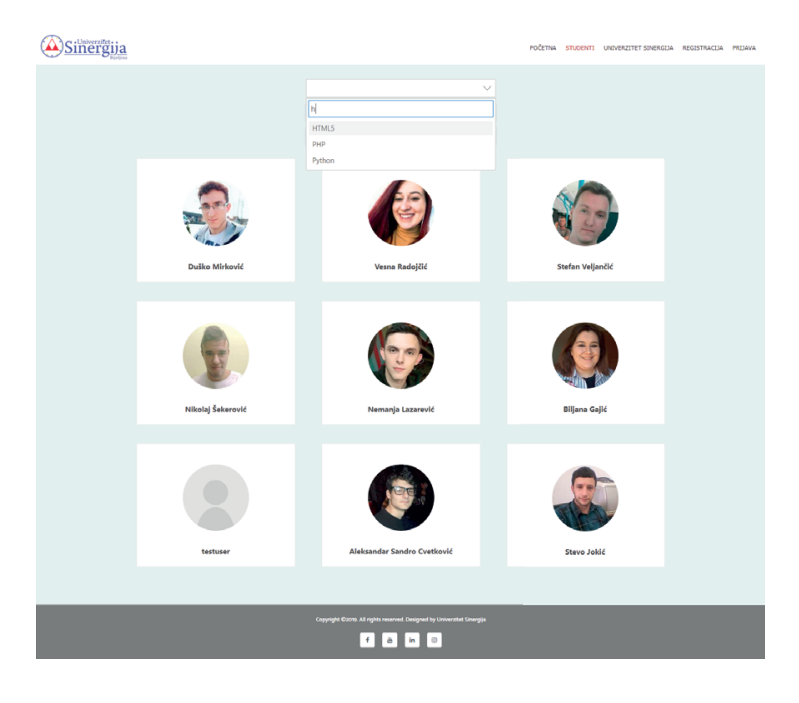

Slika 2. Lista studenata (profili studenata)

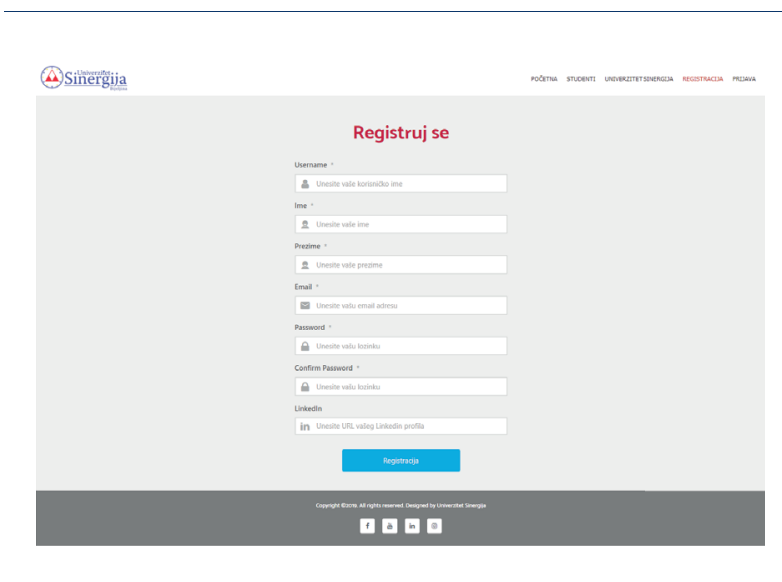

Slika 3. Forma za registraciju

Nakon što se student registrovao i kada je zvanično verifikovan od strane administratora, student ima mogućnost da se prijavi preko strane „Prijava“. Student se može prijaviti preko svoje studentske email adrese ili upotrebom korisničkog imena (Slika 4).

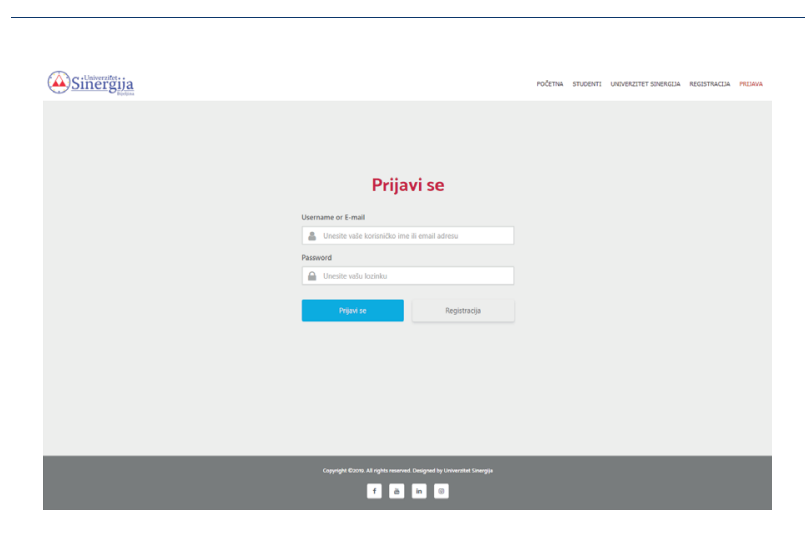

Slika 4. Forma za prijavu 


\section{Studentski profil}

Glavni deo studentskog ePortfolia je studentski profil. Kompletan ePortfolio usmeren je na studenta kao pojedinca i njegov profil. Za razliku od društvenih mreža kao što su Facebook i Instagram, studentski ePortfolio profili su više nalik LinkedIn društenoj mreži. Studenti nemaju mogućnost dodavanja bilo čega što nije profesionalno, stručnog karaktera i usmereno ka usavršavanju i razvoju karijere.

Na Univerzitetu Sinergija studenti kroz svoje školovanje rade na izradi sopsvetnih LinkedIn profila, međutim ePortfolio profil studenta donosi drugačiju vrednost. ePortfolio profil pruža preciznije informacije, npr. pomoću ePortfolia student može detaljno da objasni i prikaže svoje projekate, da navede ko su mentori koji su studenta vodili kroz projekate i na kojim predmetima su rađeni projekti. Takođe, lakše je i brže doći do kontakt podataka i kontaktirati studenta direktno nego na LinkedIn društvenoj mreži.

ePortfolio studentski profil je napravljen tačno po kalupu koji je namenjen za studenta, dok je LinkedIn profil više namenjen za profesionalce. Međutim spona između LinkedIn-a i ePortfolia povećava vidljivost studenata na internetu kao i mogućnost za menadžere ljudskih resursa (engl. Human Resource Manager) da lakše pronađu studente. HR menadžeri nisu samo u potrazi za profesionalcima, kako se IT industrija razvija sve je veća potreba za radnom snagom tako da razne kompanije nude praksu i stipendije za studente treće i četvrte godine.

Studentski ePortfolio profil se sastoji od pet sekcija. Prva sekcija obuhvata profilnu sliku studenta, LinkedIn profil i Youtube profil ukoliko ga student ima, i kao sastavni deo prve sekcije biografija studenta. Druga sekcija namenjena je isključivo stručnim veštinama koje student poseduje. Treća sekcija odnosi se na projekte na kojima je student radio. Svaki projekat ima svoj naziv, mentore, link ka lokaciji na internetu ukoliko je postavljen negde, kompletan fajl projekta, detaljan opis projekta i slike. Četvrta sekcija namenjena je svim radovima na kojima je student radio u toku svog školovanja (seminarski rad, diplomski rad, master rad, prezentacije). Svaki rad se sastoji od naziva, tipa, pdf dokumenta i detaljnog opisa, odosno apstrakta. Peta sekcija služi za prezentovanje svih sertifikata koje je student položio u toku svog školovanja (Slika 5).

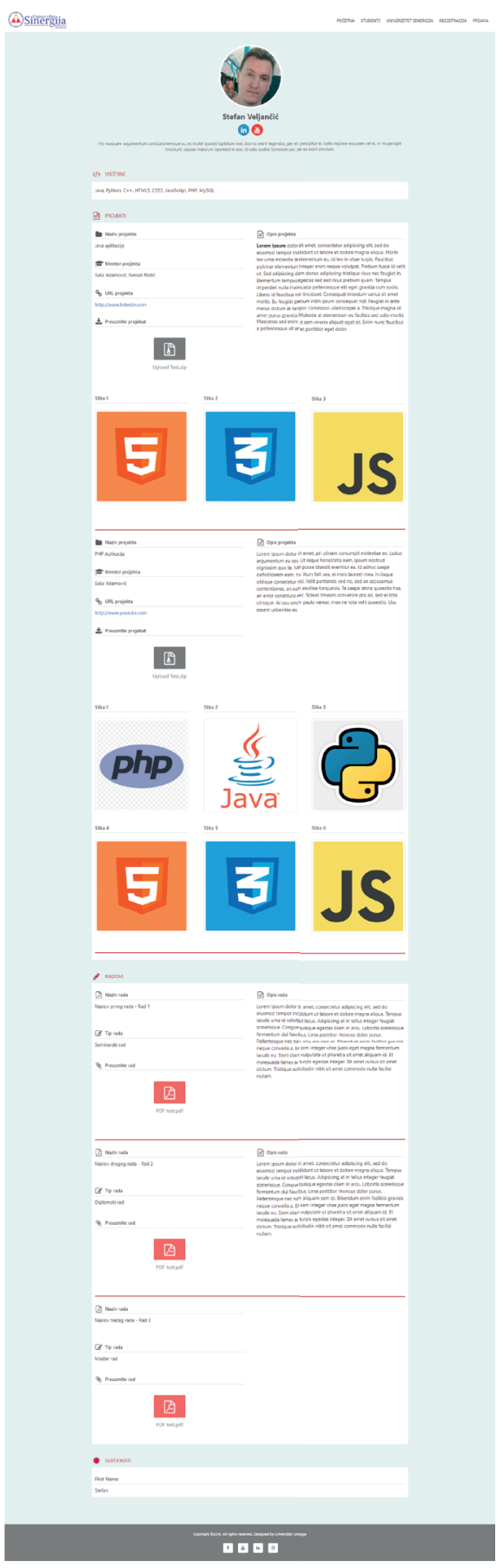

Slika 5. Profil studenta

\section{Admin panel}

Administratori uz pomoć admin panela upravljaju ePortfoliom, vrše kontrolu registrovanih profila kao i sadržaja koji studenti nakon verifikacije postavljaju na svoje profile. Profesori takođe imaju svoje mentorske profile preko kojih mogu da provere, odobre ili odbiju sadržaj koji student želi da postavi na svoj profil. Nakon što student ažurira svoj studentski ePortfolio profil 
i označi odgovarajućeg mentora za novi projekat koji je dodao, profesoru koji je označen kao mentor stiže obaveštenje na email da je postavljen novi projekat iz njegovog predmeta sa imenom i prezimenom studenta i nazivom projekta.

\section{PREDNOSTI I MANE EPORTFOLIA}

\section{Prednosti}

Kao prva prednost izdvaja se mogućnost povezivanja sa lokalnim IT kompanijama koje zapošljavaju IT stručnjake. ePortfolio i jeste platforma koja ima za cilj da što preciznije prikaže stručne sposobnosti posetiocima platforme koji su najčešće poslodavci. Pomoću ePortfolio platforme pruža se mogućnost za osnivanje saradnje sa lokalnim IT kompanijama, takođe kompanije u vidu saradnje mogu da ponude studentima zaposlenje, mogućnost stipendiranja u toku studija i obavljanje stručne prakse. ePortfolio platforma sadrži samo profile najboljih studenata i to poslodavci znaju.

Ostvarivanje saradnje sa lokalnim IT kompanijama pomoću ePortfolio platforme pomaže i prilikom usmeravanja studenata u pravom smeru za tržište rada. IT kompanije na taj način pomažu Univerzitetima da grade silabuse za predmete u koraku sa tehnologijom i prema zahtevima tržišta.

Za IT stručnjake danas važe drugačija pravila kada je u pitanju praksa. Obično studenti završe fakultet i nakon toga apliciraju za obavljanje prakse u raznim kompanijama. Kod IT struke princip je danas drugačiji baš zbog mogućnosti izrade raznih projekata u toku studija, gde student stiče odgovarajuće znanje i obavlja praksu. Od studenta se očekuje da ima odgovarajuće predznanje i dobru podlogu pre nego što počne da radi.

Jedna od značajnijih prednosti jeste povećana vidljivost studentskog CV-a na internetu. Student u kombinaciji sa LinkedIn profilom i studentskim ePortfolio profilom pokriva sve informacije koje su interesantne $\mathrm{i}$ važne za HR menadžere. Na ovaj način pomaže studentima jer se šanse da neko prepozna njihov trud i stupi u kontakt sa njima znatno povećavaju, dok sa druge strane olakšava se posao HR menadžerima jer su im svi studenti i sve informacije dostupne kroz par klikova.

ePortfolio pruža motivaciju studentima za rad u grupama, napredak i razmenu ideja. Studenti mogu da izaberu kompleksnije projekte ukoliko se podele u grupe. Studentu je jasno da mnogo više može da postigne radom u grupi nego kao pojedinac. ePortfolio platforma služi kao dokaz i spisak svih projekata koji su uspešno realizovani, zbog toga platforma motiviše studente da praktikuju timski rad i da imaju takmičarski duh. Prednost za studente jeste što se ovakav pristup primenjuje i u kompanijama.

Svi projekti dostupni na studentskim ePortfolio profilima su potpuno besplatni i dostupni svima. $\mathrm{Na}$ ovaj način ostvaruju se razni doprinosi u različitim oblastima.

ePortfolio platforma Univerziteta Sinergija uključuje SEO (engl. Search Engine Optimization). Platforma ima minimalni dizajn i napravljena je da bude jednostavna bez viška elemenata što je čini pogodnom za SEO optimizaciju. SEO znatno doprinosti ePortfoliu tako što omogućava da platforma bude dobro optimizovana za bolje pozicioniranje na web pretraživačima čime se dodatno povećava vidljivost studentskih ePortfolio profila.

Takođe kao prednost ePortfolio platforme izdvaja se pomoć prilikom opredeljenja studenata za određene oblasti. Cilj ePortfolia jeste da dokumentuje iskustvo studenta koje je stekao u toku svog školovanja. Studenti obično imaju dilemu, šta je to što ih najviše privlači i čime bi tačno hteli da se bave? U ovom cilju studentima pomažu mentori ali upotrebom ePortfolio platforme stvara se mogućnost da studenti kroz kontinualno ažuriranje svojih profila grade sliku o sebi i podstaknuti su da istražuju, pronađu i odluče koja ih oblast najviše zanima. Pored toga platforma pomaže i mentorima da lakše prepoznaju talenat i pravilno usmere studenta.

ePortfolio omogućava skladištenje projekata na jedno mesto. Ovakav način se pokazao kao dobra praksa zato što studenti vode evidenciju o svojim radovima i projektima. Sve najvažnije materijale imaju dostupne na jednom mestu i ukoliko je potrebno nekome da pokažu, sve to mogu da urade dosta brzo. Ovo je takođe važno za izgradnju IT karijere studenta, jer kasnije studenti mogu koristiti svoj profil za inspiraciju, nadogradnju starih projekata i razvoj novih ideja.

Po čemu se ePortfolio razlikuje od CV-a (engl. Curriculum Vitae)? ePortfolio Univerziteta Sinergija je usmeren ka studentu i generalno ePortfolio obično predstavlja talente koje čovek poseduje. Može da sadrži razne projekte, uzorke, slike itd. ePortfolio je kolekcija uzoraka radnih aktivnosti koje drugi ljudi poput HR menadžera mogu da testiraju.

Dok je CV generalno korišten kada je potrebno sumirati sva iskustva i veštine iz prethodnih godina. Obično se sve navodi u stavkama maksimalno dužine jednog ili dva lista. Suštinska razlika je u tome da se obično 
unutar CV-a postavlja link koji vodi ka ePortfoliu u kome se onda precizno mogu videti i testirati radne aktivnosti. Ova spona između CV-a i ePortfolia povećava šanse da kandidat dobije odgovarajući posao za koji je aplicirao.

\section{Mane}

Studentski ePortfolio profil često može da sadrži projekte gde su korištene različite verzije softvera zbog čega može da dođe do konflikta prilikom instalacije i pokretanja softvera, ukoliko se verzije ne poklapaju sa verzijama koje su korištene u projektu. Određeni projekti zauzimaju mnogo memorije i zahtevaju dodatne module za instalaciju kako bi ispravno radili što zna da bude komplikovano.

ePortfolio nije namenjen da se koristi bez upotrebe računara u toku razgovora za posao. Bez računara nije moguće testirati projekte osim u slučaju kada student ima projekte dostupne i na nekoj internet lokaciji. U sklopu studentskog ePortfolio profila postoji opcija gde student može da na svoj profil postavi i internet lokaciju projekta kada dodaje novi projekat.

Ukoliko student odgovarajuće radove nema u elektronskoj formi potrebno je da skenira sve radove i da ih pripremi u formatu koji je odgovarajući za ePortfolio.

ePortfolio treba da prezentuje kompletnu i preciznu sliku svih radnih aktivnosti i veština koje je student ostvario. Iz tog razloga potrebno je da mentori i studenti izdvoje određeno vreme kako bi profil izgledao profesionalno.

U određenim situacijama ePortfolio studentski profil se može tretirati kao manje vredan izvor u odnosu na ocene studenata.

Takođe kao mana izdvaja se da ukoliko ePortfolio profil nije dobro isplaniran i usmeren, ukoliko nije jasno definisan cilj i kriterijum, ePortfolio profil može da ostavi utisak kao kolekcija nagomilanih projekata koji ne pokazuju tragove napredovanja i dostignuća. ePortfolio sam po sebi može da sadrži mnogo različitih podataka koje je teško grupisati radi analize koja bi prikazala napredak.

\section{ZAKLJUČAK}

Studentska platforma - ePortfolio pokazala se kao kvalitetno rešenje za više različitih problema. ePortfolio pruža motivaciju studentima da zadrže kontinuitet učenja i napredovanja, da studenti budu odgovorni i posvete pažnju razvoju svoje karijere i omogućava studentima da razvijaju svoje digitalne kompetencije uz stručnu pomoć mentora.

ePortfolio pored svih prednosti koje pruža studentima, omogućava i prednosti za profesore, poslodavce i roditelje. Platforma Studentima pomaže da digitalizuju svoje radne aktivnosti i trud koji su uložili u toku školovanja čime se znatno povećava njihova vidljivost na internetu kao i šanse za zaposlenje. Profesorima ePortfolio platforma pomaže prilikom procene talenata, prednosti i mana kod studenata i budućeg usmerenja za studente koji su pod njihovim mentorstvom. Poslodavcima platforma olakšava posao tako što izdvaja sve najbitnije informacije za poslodavce i grupiše ih na jedno mesto tako da su jasno vidljive i lako dostupne. Roditeljima ePortfolio platforma omogućava da prate tok studiranja i napredovanja njihovog deteta, kao i za koje stručne oblasti se dete interesuje.

Studentska platforma ePortfolio pruža mnogo više prednosti nego što ima mana.

\section{LITERATURA}

[1] https://www.aacu.org/publications-research/periodicals/beneftis-e-portfolios-students-and-facultytheir-own-words, datum pristupanja: 14.03.2019 godine, naziv članka: benefits-e-portfolios-studentsand-faculty-their-own-words

[2] http://www.ascd.org/publications/books/197171/ chapters/The-Types-of-Portfolios.aspx, datum pristupanja: 14.03.2019 godine, naziv članka: Introduction to Using Portfolios in the classroom

[3] https://blog.cengage.com/three-reasons-eportfolios-matter-to-todays-college-students/, datum pristupanja: 14.03.2019 godine, naziv članka: Three reasons why ePortfolios Matter to Todays college students

[4] https://www.researchgate.net/publication/ 328792577_Digital_Ethics_and_the_Use_of_ ePortfolio_A_Scoping_Review_of_the_Literature, datum pristupanja: 15.03.2019 godine, naziv rada: Digital ethics and the Use of ePortfolio: A Scoping review of the literature, Autori: Teri Downer, Misty M Kirby, International Journal Of eProftfolio, 2018 Volume 8 Number 2, pp. 115-125

[5] https://www.learntechlib.org/p/43166/, datum pristupanja: 15.03.2019, Autor: Diana Challis, godine, naziv rada: Towards the mature ePortfolio: Some implications for higher education, Canadian Network for Inovation in Education: Volume 31, Number 3, 2015, ISSN: 1499-6677 
[6] https://www.researchgate.net/publication/ 299690470_Electronic_Portfolio_as_a_Knowledge_Management_Tool_A_Comparative_ Analysis, datum pristupanja: 15.03.2019 godine, Autori:Wardah Zainal Abidin, Lorna Uden, Rose Alinda Alias, naziv rada: Electronic Portfolio as a Knowledge Tool: A Comparative analysis, the $8^{\text {th }}$ international conference on knowledge management in Organizations:Social and big data Computing for Knowledge Management (pp.179-188), 2014

[7] https://www.researchgate.net/publication/ 320656165_The_Pentagonal_E-Portfolio_Model_for_Selecting_Adopting_Building_and_Implementing_an_E-Portfolio ,datum pristupanja: 15.03.2019 godine, naziv rada: The Pentagonal EPortfolio Model for Selecting Adopting Building and Implementing an E-Portfolio, Autori: Nicole Buzzetto-Hollywood, Ayodele Julius Alade, 2008
[8] https://www.researchgate.net/publication/ 315856918_The_Application_of_Eportfolio_in_ Higher_Education_implications_for_Student_Learning , datum pristupanja: 15.03.2019 godine, naziv rada: The Application of Eportfolio in Higher Education: Implication for student learning, Autor:Andrea Ximena Castano Sanchez, 2014 